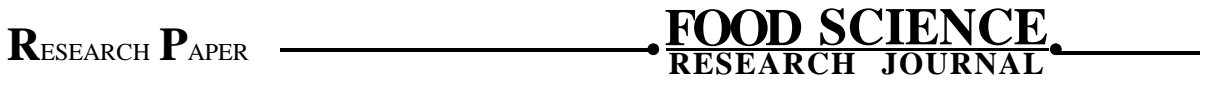

\title{
Formulation of weaning food with fortification of orange (Citrus sinensis) waste
}

\author{
M.A. Zaker, A.R. Sawate, B.M. Patil and R.B. KshiRsagar
}

The study was conducted to formulate weaning food by using sorghum, green gram, rice and foxtail millet. Different proportions of orange waste (peel and pomace powder) were incorporated at different proportions. Weaning food was prepared using roasting and malting techniques. Based on the sensory evaluation, the malted sample was selected. Out of the three formulation studies, the sample $\mathrm{T}_{3}$ was found richest in the protein $(17.07 \%)$ and fat $(4.2 \%)$ containing 30 per cent orange waste combination Powder. The mean score of different oraganoleptic characteristics of the energy food formulations showed that sample $\mathrm{T}_{2}$ containing 20 per cent orange waste combination Powder was significantly superior over sample $\mathrm{T}_{1}$ and $\mathrm{T}_{3}$ though the sample $\mathrm{T}_{3}$ containing more nutritional profile, but least accepted .The pre treatments such as malting and roasting are given to the above selected weaning food (sample $\mathrm{T}_{2}$ ) for improving their organoleptic characteristics and the results revealed that among all the four developed weaning foods, the malted food was organoleptically superior yielding a good quality product. The results on physical properties of developed weaning foods showed that the malted weaning food had the lowest density and water absorption capacity and high dispersability.

Key Words : Weaning food, Organoleptic, Malting, Roasting, Water absorption capacity, Dispersibility

How to cite this article : Zaker, M.A., Sawate, A.R., Patil, B.M. and Kshirsagar, R.B. (2017). Formulation of weaning food with fortification of orange (Citrus sinensis) waste. Food Sci. Res. J., 8(1): 83-90, DOI : 10.15740/HAS/FSRJ/8.1/83-90. 